\title{
Quality of life of men and women using drugs in Western Slovakia
}

\author{
Martina Zakova* and Martina Krajcirova \\ Trnava University in Trnava, Slovakia
}

\begin{abstract}
The aim of our research was to determine the quality of life of men and women who are current drug users in terms of their own perception. We decided to focus on gender because it can also interfere with quality of life. In particular, we aimed to investigate the main dimensions of quality of life such as health, economic situation and social ties. We used a standardized questionnaire WHOQOL BREF. The fieldwork phase of the research was realized from September 2015-December 2015. We used a snowball sampling for collecting data. We investigated that all four domains (physical health, psychological, social relationships and the environment) were evaluated worse by women than men. Women showed in relation to the fair value population the highest standard deviation in the area of psychological domain and men in social relatioships domain. The highest deviation in the areas between men and women was in the physical area. The results showed that quality of life of drug users was dimished, but not as much as we expected in terms of knowledge that literature states.
\end{abstract}

Key words: drug users, quality of life, health, social relationships and environment.

\section{Introduction}

The quality of life of people who inject drugs, is the central subject of this proceeding. It would seem that quality of life is abstract concept. The truth is that, in various forms, it is the subject of professional, non-professional, or political debates for a long time. According to Kucharova, the discussion regarding the quality of life already appeared in ancient and Eastern philosophy [1]. The issue has been discussed at the level of philosophical reflections. Many of them spilled over into the field of ethics. In ancient times, this phenomenon was called good life, well-being or social security. Such references to the quality of life can be found in the works of Aristotle, Aquinas, Socrates, Kant and others [2]. Their ideas provided the foundations for later determination of quality of life, respectively with related issues.

The term "quality of life" in the literature began to appear more frequently in the $60 \mathrm{~s}$ of the 20th century, when particularly was emphasized its economic dimension and the issue of standard of living. In the 70s, the issue was studied by many authors, but it was also studied from the perspective of various disciplines. Despite this diversity, all authors approvingly pointed out that it is necessary to focus on the area of the standard of living, quality of life and their interconnection [3]. Subjective assessment of quality of life people themselves was the subject of research but with regard to the objective conditions in which they live [2].

\footnotetext{
* Coresponding author: martina.zakova@truni.sk
} 
In the $80 \mathrm{~s}$, the quality of life started to draw attention of medical field in the context of the chronically ill care, as well as of psychology, whose quality of life was connected with the concept of psychological well-being [1, 4]. Postmaterialism [2], and postmodernism [4] influenced the quality of life in this period, in which the quality of life was linked to life values. At that time, the quality of life based on the biological, psychological and social needs of the individual. The requirement was to identify the main needs, which would have consequences to quality of life. In this regard, Todorov named indicators of quality of life as the most essential characters, respectively, indicators of subjective assessment of quality of life [3]. A little later, since the 90s of the last century, the content of quality of life in relation to sustainable development has become an important subject of expert and political discussions. Social quality will eventually become a part of strategy of the European Union [2].

At present, we cannot talk about definitive conclusions in the perception of the contents of the quality of life. According to Hermanova, the term is a normal part of a lay and political vocabulary [5]. Gurkova states that quality of life is a phenomenon with a high level of complexity [6]. Other authors state that it is interdisciplinary or multidisciplinary $[1,2,6]$ and multidimensional $[1,5-7]$ concept, as well as controversial because this concept is difficult to grasp [8].

The term quality of life appropriated a number of disciplines. There is no generally accepted definition or a clear concept of quality of life, and the theory is built by consensus. Masarova and Zivcicova talk about it as a social construct, which expresses human's need to explore, compare and evaluate his life. An emphasis is placed on the cultural context for an assessment of the individual and the specifics of communities, their needs and expectations from life to build upon the cultural patterns of behaviour [4]. Close to this definition is also one of a number of definitions of quality of life, the definition given by WHO. According to this definition, there is an individually perceived life situation in the context of a certain culture and system of values in relation to their own objectives, expectations, values and interests. Quality of life is influenced by physical health, psychological state, the level of independence, social relationships and ecological characteristics of the environment. WHO focuses on the perception of quality of life from person's own perspective [9]. In the understanding of what is quality of life, there are many approaches.

Levicka and Balogova wrote that in the past there were attempts to adopt a single comprehensive definition of quality of life. Often accepted definition of quality of life according to the authors Zannoti, Prinquey, Thauby, Lambotin, Darcout is that it is individual, subjective, and emotional state in the surroundings. It is equally influenced by social and cultural characteristics and desires [3]. Convenience of modern society is insufficient itself in relation to what person expects from a good quality of life. Total professional consensus on the definition of quality of life does not exist and perhaps never will exist, as the term is generally directly related to the complexity and sophistication of human life itself, namely from the fact that one's life is structured in de facto infinite number of coexisting internal factors plethora of interpersonal interactions and activities in the overlapping areas of interest and overlapping social groups. Finally, life of an individual can also be structured in a series of coincidences. This is also reflected in synonym confusion between the concept of quality of life of the related concepts, such as well-being, social welfare, human development, standard of living, satisfaction, etc. [5]. According to Mares, found unified universal definition may be meaningless, and could be more important to draft definition grounded in specific disciplines [10]. It is ultimately the real happening.

Veenhoven created a model of four types of quality of life (see Table 1), a categorization of the concept of quality of life from the perspective of various disciplines. These four types of quality of life are defined by dimensions of outer and inner qualities and changes 
and outcomes. This is a classification that distinguishes between good quality life and opportunities for good life, that means between the real life and chances and opportunities. And at the same time, the author distinguishes between inner and outer qualities of life, which means between what is characteristic for the environment of the person, and what is characteristic for himself [11].

Understanding and detecting the quality of life historically evolved from an objective assessment of living conditions through knowledge of subjective and cultural, social status or other perceptions of conditions to the current path to detect the quality of life as a subjective assessment of human well-being (i.e., satisfaction with the formation and survival of his life). It shows a tendency to combine quality of life with an area of preferred values and value orientations of a person (i.e., Maslow's hierarchy of human needs, and specifically with the need for self-realization), which underpins especially social psychology or regional sociology. There is a presumption that the quality of life will be increasingly associated with self-assessment of people with regard to the needs of self-actualization and life satisfaction and fulfilment of the meaning of life [8].

Kirby does not include living standards in the quality of life, but he includes satisfaction with standard of living. It defines three perspectives measuring quality of life:

a) objective measurement of social indicators, which is designed to measure the collective quality of life in terms of opportunities, barriers and resources surrounding the area;

b) subjective estimate of overall satisfaction with life, where the individual is trying to evaluate it through personal values and lifestyle;

c) estimate of subjective satisfaction with the individual cues, which are many $[1,12]$.

Women can have different response to using drugs than men. They may have more drug cravings, more physical effects on their heart and blood vessels, they may be more likely to have anxiety, depression or panic attacks [13]. If there are differences between women and men in effects of drugs there can be also differences in their quality of life.

\section{Methodology and participants}

The aim of our research was to find out how drug users assess the quality of their life if there are differences in the quality of life of active drug users depending on gender. In order to conduct the study we used a quantitative research strategy. Respondents self-completed WHOQOL-BREF questionnaire. It is internationally validated. Our results we compare with healthy population [14].

The structure of the research methodology included socio-demographic characteristics: gender, age, type of the drug used, duration of the use, and way of application and evaluation of current health status in order to provide a picture of the survey sample. The task of respondents was to apply a 5-point Likert scale to assess their subjective satisfaction with individual health and quality of life. WHOQOL-BREF consists of 26 items and is a shortened version of the questionnaire WHOQOL-100. This abbreviated version of the WHOQOL100 was created by selecting at least one question from each of 24 facets relating to quality of life as well as 2 items that rate overall subjective quality of life and satisfaction with health. The questionnaire is divided into 4 potentially independent domains: physical health, psychological, social relationships, and environment. Domain scores for the WHOQOLBREF are calculated by taking the mean of all items included in each domain and multiplying by a factor of four. Domain scores were transformed to a score out of 100, with higher scores indicated a better quality of life [15]. This questionnaire defines the quality of respondents' life as a subjective perception. 
Table 1. Types of used drugs.

\begin{tabular}{|l|c|c|c|c|}
\hline Gender & Methamphetamine (n/\%) & Heroin $(\boldsymbol{\%})$ & Marihuana $(\boldsymbol{\%})$ & Alcohol (\%) \\
\hline Male & 100 & 92.3 & 30.8 & 23.1 \\
\hline Female & 100 & 71.4 & 14.3 & 0 \\
\hline
\end{tabular}

Table 2. Way of using drugs.

\begin{tabular}{|l|c|c|c|}
\hline Way of using drugs & Injection (\%) & Smoking (\%) & Drinking (\%) \\
\hline Mender & 100 & 30.8 & 23.1 \\
\hline Female & 100 & 14.3 & 0 \\
\hline
\end{tabular}

The data was analysed using descriptive statistics, correlation analysis and statistical tests. We used the $F$-test and two tail Students $t$-test, Pearson correlation coefficient and we used Excel and Statistica software. The obtained data were divided into two main groups according to the gender because we wanted to know if there are any differences.

In Slovakia, we do not have many researches of drug users. Respondents of these researches were usually clients of treatment facilities but not people who actually use drugs. Our sample consisted of men and women of different ages who were users of illegal drugs and alcohol at the time of collecting data. Our respondents were clients of street workers working in western part of Slovakia and their friends. $65 \%$ men and 35\% women were involved in the research. The average age of respondents was 37 . The youngest respondent was 29 years old and the oldest respondent was 55 years old. Majority of the respondents began using drugs at the age on average between $20-21$ years.

\section{Results}

We started with the question about length of drug use. Average length of drug use was 16 years for men and 17 years for women which is a long time. This information was very interesting for us because we had an opportunity to find out new information about long-time drug users and how they perceive their quality of life. Next question focused on the type of drugs used by respondents.

All respondents regardless of gender were taking methamphetamine. In comparison, Schneiderova wrote that the most used drug in Slovakia was heroin [15]. This information is from 2013 and we understand that situation could change, but our sample was not taken from all parts of Slovakia, and we also did not have a representative sample. Heroin was used by 92.3\% males and $71.4 \%$ females. $30.8 \%$ men and $14.3 \%$ women use marihuana. $23.1 \%$ men and no women use alcohol. This combination can cause complications in treatment and risk of fatal overdose. With this combination of drugs there are more overdoses [16]. The results on way of using drugs are seen in Table 2 by gender (respondents could choose from several options).

All respondents inject drugs. $30.8 \%$ of men smoke drugs, $14.3 \%$ of women smoke drugs. These data connecting with using Marihuana. $23.1 \%$ of male respondents reported that they drink alcohol. Use of drugs injecting them is the most dangerous way. It influences physical health of drug users the most [17]. We examined respondents current health status.

$65.0 \%$ of respondents reported that they are currently ill. Among respondents who answered positively, were $61.5 \%$ men and $71.4 \%$ women. Respondents had opportunity to write which disease have. 
Table 3. Current health status.

\begin{tabular}{|l|c|c|c|c|c|c|}
\hline \multicolumn{7}{|c|}{ Are you currently ill? } \\
\hline Gender & Yes (n) & Yes (\%) & No (n) & No (\%) & Total (n) & Total (\%) \\
\hline Male & 56 & 61.5 & 35 & 38.5 & 91 & 100.0 \\
\hline Female & 35 & 71.4 & 14 & 28.6 & 49 & 100.0 \\
\hline Total & 91 & 65.0 & 49 & 35.0 & 140 & 100.0 \\
\hline
\end{tabular}

Table 4. Diseases of respondents.

\begin{tabular}{|c|c|c|c|c|c|c|c|c|c|}
\hline Disease & Hepatitis C & Phlebitis & Influenza & Paranoia & Headache & $\begin{array}{c}\text { Problems } \\
\text { with teeth }\end{array}$ & Thrombosis & $\begin{array}{c}\text { Did not } \\
\text { write }\end{array}$ & Total \\
\hline$\%$ & 20.0 & 10.0 & 5.0 & 5.0 & 5.0 & 5.0 & 5.0 & 10.0 & 65.0 \\
\hline
\end{tabular}

Table 5. Q1 How do you rate your quality of life? - two-tail test.

\begin{tabular}{|l|r|c|}
\hline $\boldsymbol{T}$-test & Male & Female \\
\hline Median & 2.15 & 2 \\
\hline Measure of spread & 0.81 & 1 \\
\hline Common variance & 0.87 & \\
\hline Hyp. difference median & 0 & \\
\hline$T$ Stat & 0.35 & \\
\hline$P(T \leq t)$ one-tail & 0.36 & \\
\hline$T$ Critical one tail & 1.73 & \\
\hline$P(T \leq t)$ two-tail & 0.73 & \\
\hline$t$ Critical two-tail & 2.10 & \\
\hline
\end{tabular}

The most reported disease was hepatitis $\mathrm{C}$ (20.0\% of respondents), $10.0 \%$ respondents reported phlebitis. These diseases are mainly related to the use by injecting drug. $5.0 \%$ of respondents suffered from diseases such as influenza, paranoia, headache, toothache and thrombosis. $10.0 \%$ respondents, despite the statement that they are currently ill, did not report any specific disease. Machova and Kubatova (2015) investigated that disease limits the ability of an organism to cope with certain problems of the internal and external environment without compromising life functions [18].

\subsection{Evaluation questionnaire WHOQOL-BREF}

We wanted to know if there was a statistically significant association between the gender of respondents and their opinion on their quality of life. We got answers to question 1 in the questionnaire - How do you rate your quality of life? Likert scale options offered answers: very poor - poor - neither poor nor good - good - very good. We used the F-test to find differences between males and females.

Whereas the level for $F$-test had a value of 0.35 (which is greater than the significance level of 0.05 , it follows that the variances are the same), we used two-tail $t$-test for equal variances. 
Table 6. Q2 How satisfied are you with your health? - two-tail test.

\begin{tabular}{|l|l|c|}
\hline $\boldsymbol{T}$-test & Male & Female \\
\hline Median & 2.69 & 2.29 \\
\hline Variance & 1.06410 & 1.57 \\
\hline Common variance & 1.23 & \\
\hline Hyp. difference median & 0 & \\
\hline$T$ Stat & 0.78 & \\
\hline$P(T \leq t)$ one-tail & 0.22 & \\
\hline$T$ Critical one tail & 1.73 & \\
\hline$P(T \leq t)$ two-tail & 0.44 & \\
\hline$t$ Critical two-tail & 2.10 & \\
\hline
\end{tabular}

Table 7. QOL domains and respondents gender.

\begin{tabular}{|c|l|c|c|c|c|c|c|}
\hline Domain & Gender & Mean score & SD & Lower boundary & Upper boundary & Min & Max \\
\hline \multirow{2}{*}{1} & Male & 11.70 & 2.35 & 9.30 & 14.00 & 14.00 & 26.00 \\
\cline { 2 - 8 } & Female & 9.90 & 2.34 & 7.50 & 12.22 & 11.00 & 23.00 \\
\hline \multirow{2}{*}{2} & Male & 11.59 & 2.06 & 9.52 & 13.65 & 13.00 & 25.00 \\
\cline { 2 - 8 } & Female & 11.24 & 1.93 & 9.30 & 13.17 & 13.00 & 21.00 \\
\hline \multirow{2}{*}{3} & Male & 10.77 & 3.28 & 7.48 & 14.05 & 5.00 & 13.00 \\
\cline { 2 - 8 } & Female & 9.14 & 1.66 & 7.48 & 10.80 & 5.00 & 9.00 \\
\hline \multirow{2}{*}{4} & Male & 10.50 & 3.07 & 7.42 & 13.57 & 12.00 & 30.00 \\
\cline { 2 - 8 } & Female & 9.71 & 2.85 & 6.86 & 12.56 & 12.00 & 30.00 \\
\hline
\end{tabular}

The level of statistical significance for two-tail test $P(2)=0.73$, so we can say that there is not statistically significant connection between the quality of life of our respondents and their gender.

Then we wanted to know if there is a statistical significance between gender of our respondents and their satisfaction with their health (questions 2 in the questionnaire How satisfied are you with your health?). Likert scale offered answers: very dissatisfied dissatisfied - neither satisfied, nor dissatisfied - satisfied - very satisfied. We again used $F$-test. The level of statistical significance for $F$-test has a value of 0.26 (which is greater than the significance level of 0.05 , it follows that the variances are the same), we used two-tail $t$-test for equal variances.

As we can see in the Table 6 , there is not statistically significant correlation between satisfaction with the health and gender of the respondents $(P(2)=0.44)$.

We wanted to know if there was a statistical significance in all domains of quality of life and gender of our respondents.

Domain 1 contains three aspects of physical health and four aspects of physical independence (pain, need of medical treatment to function in their daily life, energy, sleeping, mobility, day-to-day activities, capacity for work). Raw domain score is 7-35, raw domain score is $1-5$. The highest score (4.08) was reported by men in question no. 15 (ability to get around), the lowest score (1.57) was reported by women in question no. 10 (energy for everyday life). 
Table 8. Physical health - two-tail test.

\begin{tabular}{|l|c|c|}
\hline $\boldsymbol{T}$-test & Male & Female \\
\hline Median & 2.92 & 2.47 \\
\hline Variance & 0.38 & 0.40 \\
\hline Common variance & 0.38 & \\
\hline Hyp. difference median & 0 & \\
\hline$T$ Stat & 1.56 & \\
\hline$P(T \leq t)$ one-tail & 0.07 & \\
\hline$T$ Critical one tail & 1.73 & \\
\hline$P(T \leq t)$ two-tail & 0.14 & \\
\hline$t$ Critical two-tail & 2.10 & \\
\hline
\end{tabular}

Domain 2 (psychological) contains 6 aspects (enjoying of life, meaningfulnes of life, concentration, self-satisfaction, acceptation of bodily appearance, negative feelings). Raw domain score is $6-30$, raw domain score is $1-5$. The highest score (4.00) was reported by women in question no. 26 (frequency of negative feelings), the lowest score (1.57) was reported again by women in question no. 19 (self-satisfaction).

Domain 3 contains 3 aspects of social relationships (personal relationships, social support - practical help from friends, sex life). Raw domain score is 3-15, raw domain score is 1-5. The highest score (2.92) was reported by men in question no. 21 (satisfaction with their sex life) and the lowest score (2.0) was reported by women in question no. 20 (satisfaction with relationships).

Domain 4 (environment) includes 8 aspects of the environment (feeling safe, healthy physical environment, financial situation, accessibility of health services, leisure activities, satisfaction with transport, avaibility of information for daily life). Raw domain score is $8-40$, raw domain score is $1-5$. The highest score (3.43) was reported by women in question no. 13 (avaibility of information for everyday life), the lowest score (1.57) was reported by women in question no. 14 (opportunity for leisure activities).

We used the $F$-test to find out difference in physical health of our respondents (domain 1) and their gender. The level of statistical significance for $F$-test had a value of 0.44 , which means that there was not statistically significant difference between male and female respondents and their physical health. We continued with the two-tail $t$-test of the same scatter.

$P(2)$ was 0.14 which means that there was no statistically significant difference in physical health assessment and gender of our respondents.

We used $F$-test to find out the difference in domain 2 and gender of our respondents. The level of statistical significance for $F$-test reached 0.50 , results showed that there was not statistically significant difference in domain 2 and gender of respondents. We continued with the two-tail $t$-test of the same scatter.

The level of statistical significance for the two-tail test $P(2)$ was 0.72 , so there was not statistically significant difference in psychological domain assessment and gender of our respondents.

Domain 3 (social relationships) - the level of statistical significance for $F$-test was 0.06 , which showed that there was not statistically significant difference in social relationships domain and gender of our respondents. We continued with the two-tail $t$-test of the same scatter. 
Table 9. Psychological - two-tail test.

\begin{tabular}{|l|c|c|}
\hline $\boldsymbol{T}$-test & Male & Female \\
\hline Median & 2.90 & 2.81 \\
\hline Variance & 0.29 & 0.27 \\
\hline Common variance & 0.28 & \\
\hline Hyp. difference median & 0 & \\
\hline$T$ Stat & 0.35 & \\
\hline$P(T \leq t)$ one-tail & 0.36 & \\
\hline$T$ Critical one tail & 1.73 & \\
\hline$P(T \leq t)$ two-tail & 0.72 & \\
\hline$t$ Critical two-tail & 2.10 & \\
\hline
\end{tabular}

Table 10. Social relationships - two-tail test.

\begin{tabular}{|l|c|c|}
\hline $\boldsymbol{T}$-test & Male & Female \\
\hline Median & 2.69 & 2.29 \\
\hline Variance & 0.73 & 0.20 \\
\hline Common variance & 0.55 & \\
\hline Hyp. difference median & 0 & \\
\hline$T$ Stat & 1.17 & \\
\hline$P(T \leq t)$ one-tail & 0.13 & \\
\hline$T$ Critical one tail & 1.73 & \\
\hline$P(T \leq t)$ two-tail & 0.26 & \\
\hline$t$ Critical two-tail & 2.10 & \\
\hline
\end{tabular}

There was no significant difference in social relationships assessment and gender of our respondents because the level of statistical significance for the two-tail test $P(2)$ was 0.26 .

We also wanted to know if there was a statistical significance in environment assessment and gender of our respondents. The achieved level of statistical significance for the $F$-test was 0.48 , which showed that there was not statistically significant difference in environment and gender of our respondents. We used two-tail $t$-test of the same scatter.

The level of statistical significance for the two-tail test $P(2)$ was 0.60 , so results showed that there was not significant difference in environment assessment and gender of our respondents.

\subsection{The final score of domains and comprehensive analysis of the questionnaire}

A detailed analysis of Question 1, Question 2 and each domain, we investigated that men had higher scores in all domains compared to women.

When we compared scores of our respondents with healthy population we investigated some differences [14]. Women reported diminished quality of life in all domains and in Q1 and Q2. Men reported diminished quality of life in Q1 and Q2 and in all domains instead of domain 1 . We compiled a correlation matrix of 4 domains depending on the gender of 
Table 11. Environment - two-tail test.

\begin{tabular}{|l|c|c|}
\hline $\boldsymbol{T}$-test & Male & Female \\
\hline Median & 2.65 & 2.43 \\
\hline Variance & 0.64 & 0.59 \\
\hline Common variance & 0.62 & \\
\hline Hyp. difference median & 0 & \\
\hline$T$ Stat & 0.53 & \\
\hline$P(T \leq t)$ one-tail & 0.30 & \\
\hline$T$ Critical one tail & 1.73 & \\
\hline$P(T \leq t)$ two-tail & 0.60 & \\
\hline$t$ Critical two-tail & 2.10 & \\
\hline
\end{tabular}

Table 12. The final score of domains.

\begin{tabular}{|l|l|c|c|c|}
\hline & & Male & Female & Norms for healthy subjects \\
\hline Domain 1 & Physical Health & 11.70 & 9.90 & 11.49 \\
\hline Domain 2 & Psychological & 11.59 & 11.24 & 14.80 \\
\hline Domain 3 & Social Relationships & 10.77 & 9.14 & 14.93 \\
\hline Domain 4 & Environment & 10.50 & 9.71 & 13.41 \\
\hline Q1 & Quality of life & 2.15 & 2.00 & 3.82 \\
\hline Q2 & $\begin{array}{l}\text { How satisfied are you with } \\
\text { your health? }\end{array}$ & 2.69 & 2.28 & 3.68 \\
\hline
\end{tabular}

Table 13. Correlation matrix of 4 domains depending on the gender.

\begin{tabular}{|l|c|c|c|c|c|c|}
\hline Gender & Average & Standard deviation & $\boldsymbol{R}(\boldsymbol{X}, \boldsymbol{Y})$ & $\boldsymbol{r}^{\mathbf{2}}$ & $\boldsymbol{t}$ & $\boldsymbol{p}$ \\
\hline Male & 2.78 & 0.15 & & & & \\
\hline Female & 2.49 & 0.22 & 0.62 & 0.62 & 1.11 & 0.38 \\
\hline
\end{tabular}

Table 14. Correlation matrix of Q2/ domain 1.

\begin{tabular}{|l|c|c|c|c|c|c|}
\hline Analysis Q2/D1 & Average & Standard deviation & $\boldsymbol{r}(\boldsymbol{X}, \boldsymbol{Y})$ & $\boldsymbol{r}^{\mathbf{2}}$ & $\boldsymbol{t}$ & $\boldsymbol{p}$ \\
\hline Q2 - satisfaction with health & 2.55 & 1.10 & & & & \\
\hline D1-physical health & 2.76 & 0.64 & 0.44 & 0.20 & 2.13 & 0.047 \\
\hline
\end{tabular}

the respondents. For $t=1.11$ was $p=0.38$, which means that the variables (male/female) did not correlate with each other. Pearson correlation coefficient $r=0.38$ showed weak correlation and independent variables.

The subsequent analysis revealed whether the answer to question no. 2 ("Are you satisfied with your health?" - Q2) is related to the results in domain 1 (physical health) without gender difference or other variables.

For $t=2.13$ is $p=0.047$. The resulting $p$-value was smaller than the significance level $\alpha=0.05$ and therefore we can say that the question Q2 correlated with results in the domain 1. Pearson correlation coefficient $r=0.44$ showed a medium strong correlation. 
Table 15. Correlation matrix of Q1/ domain 1-4.

\begin{tabular}{|l|c|c|c|c|c|c|}
\hline Analysis Q1/ all domains & Average & Standard deviation & $\boldsymbol{r}(\boldsymbol{X}, \boldsymbol{Y})$ & $\boldsymbol{r}^{\mathbf{2}}$ & $\boldsymbol{t}$ & $\boldsymbol{p}$ \\
\hline Q1 - quality of life & 2.10 & 0.91 & & & & \\
\hline D1-D4 & 2.69 & 0.58 & 0.83 & 0.69 & 6.39 & 0.000005 \\
\hline
\end{tabular}

The last analysis was to prove whether the quality of life perception (question 1-Q1) and the answers to the remaining questions (domain 1-4) are related without distinction to the variable.

The results showed that for $t=6.39$ was $p=0.0000005$. The resulting $p$-value was smaller than the significance level $\alpha=0.05$ and therefore we can say that the answers to Q1 correlated with the results of all 4 domains. Pearson correlation coefficient $r=0.83$ showed a strong correlation

As we wrote above, we do not have surveys or researches on quality of life of active drug users in Slovakia. We had some researches which are on quality of life of drug dependent people which were realized during their treatment. One of the latest realized Hudakova and Magurova. These authors conducted research on the impact of alcoholism on women's quality of life. They used a questionnaire (WHOQOL-BREF) for patients diagnosed with chronic alcoholism. $30 \%$ of women said they had a very poor quality of life. In up to $70 \%$ of women surveyed occurred persistence of increased frequency of negative feelings. Only $36 \%$ of women declared satisfaction with their family life and their surroundings. Many of these women were aware that their alcohol dependence had a substantial negative impact on the financial situation of their household and in social relations. Most problems were found precisely in the social sphere and in the field of mental well-being [19].

Dolezalova carried out a study that charted the subjective quality of life of drug users in therapeutic communities. She analyzed their differences from the control group, which consisted mainly from students. She used SQUALA questionnaire. Overall, in most areas of importance significant difference expressed between clients of therapeutic communities and the control group. Clients in treatment centers considered the most important self-care, psychological well-being and freedom. The control group put on first place health, followed by caring for each other, psychological well-being and freedom. Slight differences were reflected in the psychological well-being, love and health. Clients of therapeutic communities reported lower satisfaction with financial status, followed by love, sex, work, hobbies, family and interpersonal relationships. Significantly less they expressed satisfaction with physical autonomy, safety, home and sleep [20].

Giacomuzzi et al. used Health-Related Quality of Life questionnaire and they found not much different perception of quality of life by women and men [21], but Wisniewski et al. found that women perceived their quality of life worse than men [22], de Campos Moreira et al. found that women also perceived their quality of life worse than men in 4 domains (psychological, social, environment and self-assessment) [23]. But other authors showed that men reported the poorer quality of life scores than women in all domains [24, 25].

\section{Conclusions}

We investigated that our respondents assess diminished quality of their lives almost in all domains and first 2 questions. We found that every domain (physical health, psychological, social relationships and environment) was evaluated worse by women than men. This information surprised us, as we thought that men would evaluate their quality of life worse than women. It could be caused by the fact that women may be more aware of changes in their 
health. Our respondents use drugs for a long time, their way of using is very risky and they use risky drugs but we have to say that satisfaction with quality of life of our respondents, physical health and psychological area was better than we expected. The impacts of drug abuse on human health, reported in the literature, are very negative and devastating. Therefore, we expected our respondents to report diminished quality of their life.

We know that our research has several limitations. Our research cannot be generalized to whole population of drug users. We suggest that the fact that we have not substantiated the statistical deviation in the quality of life of drug users can also be affected by the fact that the WHOQOL Questionnaire is a subjective assessment and thus carries all the subjective features of the current drug user's perception of itself, its influence on its surroundings. It would be interesting to find some differences in the quality of life depending on the drug used, but our respondents were users of more than 1 type of drug, so it was not possible to do. It would be also interesting to compare our findings with more other studies, but there are more researches of drug addicted respondents in treatment facilities, but no active drug users. This situation results from the very complicated possibility of finding drug users willing to cooperate. Drug addiction is a chronic disease and quality of life can be an excellent measure because it adds the encouragement of improves the satisfaction with the life [22] and is it important for professionals work with these clients.

This paper was prepared as a part of the project The Identity of Social Work in the Context of Slovakia [APVV-0524-12] funded by the Slovak Research and Development Agency.

\section{References}

[1] B. Kucharova, edited by P. Tomanek. Vnimanie kvality zivota klientami resocializacnych stredisk v Slovenskej republike (Galanta, Cisty den, 2011), p. 66, ISBN: 1336-4243

[2] M. Antalova, I. Laluha, A. Privara, Kvalita zivota (Ekonom, Bratislava, 2013), p. 316, ISBN: 978-80-225-3596-0

[3] J. Levicka, B. Balogova, Kvalita života a jej odraz v socialnej praci. edited by J. Levicka, et al., Socialna praca 2 (Oliva, Trnava, 2009), p. 162, ISBN: 978-80-8933206-9

[4] T. Masarova, E. Zivcicova, Meranie kvality zivota. p. 206, ISBN: 978-80-8154-003-5. (Georg, Zilina, 2012)

[5] E. Hermanova, Koncepty, teorie a mereni kvality zivota (Sociologickenakladatelstvi, Praha, 2012), p. 235, ISBN: 978-80-7419-106-0

[6] E. Gurkova, Hodnocení kvality života: Pro klinickou praxi a ošetřovatelský výskum.224 s (Grada, Praha, 2011), ISBN: 978-80-247-3625-9

[7] J. Dzuka, et al., Psychologicke dimenzie kvality života. [online] (Presovska univerzita: Presov, 2004). Available on: http://www .pulib.sk/elpub2/FF/Dzuka3/05.pdf

[8] E. Hermanova, Kvalita zivota a jeji modely $v$ soucasnem socialnim vyskumu. Sociologia [online]. 4, 407-425 (2012). Available on: https://www.sav.sk/ journals/uploads/09101219Hermanova\%20\%200K\%20upravena $\% 20$ studia.pdf. ISSN 1336-8613 (2012)

[9] WHOQOL. Measuring quality of life: The World Health organization quality of life instruments. [online] (Geneva: WHO, 1997). Available on: http://www . who.int/mental_health/media/68.pdf

[10] Mares edited by M. Kacmarova et.al. Teorie a nastroje merania subjektivne hodnotenej kvality zivota (Filozoficka fakulta Presovskej univerzity, Prešov, 2013) 254 p., ISBN: 978-80-555-0972-3 
[11] R. Veenhoven, edited by M. McGillivray \& M. Clark (Eds.) "Understanding Human Well-being" (United Nations University Press, Tokyo-New York-Paris, 2006) p. 74-100, ISBN: 92-808-1130-4

[12] P. Muhlpachr. Mereni kvality života jako metodologicka kategorie. edited by Kvalita zivota a rovnost prilezitosti $-\mathrm{z}$ aspektu vzdelavania dospelych a socialnej prace. (Presovska univerzita, Presov, 2005) 908 p., ISBN: 8080684251

[13] Sex and Gender Differences in Substance Use [online]. Available on: https://www.drugabuse.gov/publications/drugfacts/substance-use-inwomen

[14] E. Dragomirecka, J. Bartonova. WHOQOL-BREF, WHOQOL-100 (Psychiatrické centrum, Praha, 2006)

[15] WHOQOL. Questionnaire WHOQOL-Bref [online] (WHO: Geneva, 1997). Available on: http: //www. emcdda. europa.eu/html.cfm/index10400EN.html

[16] S. Schneiderova, et al., Drogy (Mlade leta, Bratislava, 2003) p. 127, ISBN: 80-10-00087-6

[17] Predavkovanie a kombinovanie drog [online]. Available on: http://www. drogy.org)

[18] J. Machova, D. Kubatova et al., Vychova ke zdravi (Grada, Praha, 2015), p. 312, ISBN: 978-80-271-0984-4

[19] A. Hudakova, D. Magurova, Adiktologie 3(11), 148-154 (2011)

[20] P. Dolezalova, Adiktologie 1(6), 14-22 (2006)

[21] S.M. Giacomuzzi et al., Eur. Addict. Res. 11, 69-75 (2005)

[22] A.B. Wisniewski et al., J. NeuroVirology 11, 138-143 (2005)

[23] T. de Campos Moreira et al., Ciencia \& Saude Colectiva 18(7), 1953-1962 (2013)

[24] S. Lima et al., Qual. Life Res. 14(2), 473-8 (2005)

[25] A. Domingo-Salvany et al., Health and Quality of Life Outcomes 8, 145 (2010) Available on: https://www.hqlo.com/content/8/1/145 